Categoria

Trabalho Acadêmico\Resumo Expandido

Titulo do Trabalho

\title{
OCORRÊNCIA DE HORMÔNIOS ESTROGÊNICOS NO AMBIENTE
}

Nome do Autor (a) Principal

Ana Beatriz Marchini Tenália

Nome (s) do Co-autor (a) (s)

Tsunao Matsumoto; Letícia de Oliveira Manoel.

Nome (s) do Orientador (a) (s)

Prof. Dr. Tsunao Matsumoto

Instituição ou Empresa

Universidade Estadual Paulista "Júlio de Mesquita Filho"- UNESP/FEIS

Instituição (s) de Fomento

E-mail de contato

anabeatriz_mt@yahoo.com.br

Palavras-chave

Disruptores endócrinos, Estrógenos. Efluentes.

\section{INTRODUÇÃO}

Os usos múltiplos da água, tais como abastecimento público, industrial e agrícola, requerem qualidade e padrões específicos, ou seja, condições físicas, químicas e biológicas adequadas às respectivas finalidades. Contudo, ao mesmo tempo em que um corpo d'água é utilizado para o abastecimento público, pode ser o receptor de efluentes 


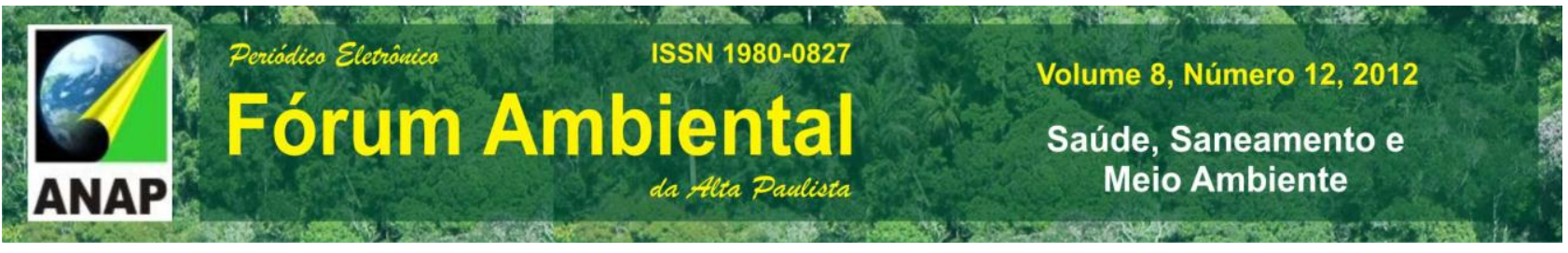

urbanos e industriais, modificando suas características, justificando assim a necessidade de um tratamento prévio ao lançamento (OTOMO, 2010).

Com o passar do tempo, novos contaminantes são gerados ou tem sua periculosidade reconhecida e assim, recebem em um tempo, nem sempre hábil, a atenção dos envolvidos com o saneamento e com a saúde publica (BIANCHETTI, 2008).

Nos últimos anos, um grupo específico de compostos químicos tem merecido atenção do meio cientifico, embora alguns pesquisadores já demonstrassem efeitos endócrinos de agentes químicos no passado, o termo Disruptor Endócrino (DE), do inglês "endocrine disruptor", começou a ser empregado em 1991 pela zoóloga Theo Colburn, para denominar agentes ou substâncias químicas presentes no meio ambiente, capazes de se acumular no solo e nos sedimentos dos rios, contaminarem a cadeia alimentar, se ligar a receptores endócrinos e promover alterações na síntese, secreção, metabolismo e/ou ação hormonais (FONTENELE et al., 2010).

Os DEs podem passar para a rede de esgoto através de urina, fezes de humanos e animais ou pelo lançamento de efluentes industriais de maneira inadequada em corpos d'água (SANTOS et al., 2007).

Segundo Reis Filho et al. (2006), dentre os DEs, os estrógenos vêm recebendo maior atenção por serem compostos extremamente ativos biologicamente e estarem relacionados à etiologia de vários tipos de cânceres. Os estrógenos naturais $17 \beta$ estradiol, estriol, estrona e o sintético $17 \alpha$-etinilestradiol, desenvolvido para uso médico em terapias de reposição e métodos contraceptivos, são os que despertam maior preocupação, tanto pela potência como pela quantidade continuamente introduzida no ambiente. Estes hormônios possuem a melhor conformação reconhecida pelos receptores, portanto, resultam em respostas máximas, sendo considerados como responsáveis pela maioria dos efeitos disruptores desencadeados pela disposição de efluentes.

Os hormônios $17 \beta$ - estradiol e 17a-etinilestradiol são excretados diariamente, por humanos e animais, no esgoto doméstico. Essas substâncias vêm sendo detectadas em efluentes de estações de tratamento de esgoto e em águas superficiais, devido às plantas de tratamento de esgoto receberem esses estrogênios e apenas eliminá-los parcialmente durante o processo de tratamento, sendo o residual descartado nos corpos receptores (FERREIRA, 2008). 
Se as águas do corpo receptor forem captadas para abastecimento humano, a jusante do ponto de lançamento, novas pessoas estarão expostas aos seus efeitos, caso as estações de tratamento de água (ETAs) também não apresentarem remoção eficiente para os hormônios. Ou ainda, se o efluente ou o lodo de uma estação de tratamento de esgotos forem utilizados para irrigação ou piscicultura, novas fontes de exposição estarão configuradas (BIANCHETTI, 2008).

\section{OBJETIVO GERAL}

Este trabalho teve como objetivo realizar revisão de literatura acerca dos níveis de estrógenos presentes em corpos d'água e efluentes domésticos.

\section{METODOLOGIA}

A metodologia do trabalho envolve a revisão de literatura a fim de verificar os estudos sobre os níveis de estrógenos naturais e sintéticos presentes em corpos d'água.

\section{RESULTADO (S)}

Furuichi et al. (2004) verificaram a presença de alguns perturbadores (entre eles, 4nonilfenol, 4-tert-octilfenol, bisfenol, etinilestradiol, estrona e $17 \beta$ - estradiol) em cinco pontos do rio Tama, no Japão. Apesar de algumas substâncias como o nonilfenol, octilfenol e bisfenol terem sido encontradas em concentrações superiores aos dos hormônios (51,6-147 $\mu \mathrm{g} / \mathrm{l}, 6,9-81,9 \mu \mathrm{g} / \mathrm{l}$ e 8,2-73,9 $\mu \mathrm{g} / \mathrm{l}$, repectivamente), a maior causa de atividade estrogênica no rio Tama foi atribuído à estrona e $17 \beta$ - estradiol que sugere o maior potencial de perturbador endócrino desta substância.

$\mathrm{Na}$ Áustria amostras de água foram coletadas em locais de rotina do controle de qualidade da água perfazendo um total de 27 pontos de medidas em águas superficiais e $59 \mathrm{em}$ águas subterrâneas. Os perturbadores analisados foram: $17 \beta$-estradiol, estriol, estrona, $17 \alpha$ - etinilestradiol, 4-nonilfenol, 4-nonilfenoletoxilato e produtos de suas degradações, octilfenol e octifenol-etoxilato, além, do bisfenol. Em mais da metade das amostras em águas superficiais o $17 \beta$ - estradiol e a estrona puderam ser detectados, 
porém, em baixas concentrações, em média, de 0,13 e 0,35 $\mu \mathrm{g} / \mathrm{l}$, respectivamente. Nas amostras de água subterrânea, o $17 \beta$ - estradiol foi detectado em $50 \%$ das amostras com valor máximo de 0,79 $\mu \mathrm{g} / \mathrm{l}$ (BURSCH et al., 2004).

Em outro estudo, também relacionado ao Brasil, discutido por Ternes et al. (1999) foram encontrados estrogênios naturais e contraceptivos sintéticos na ETE (Estação de Tratamento de Efluentes) da Penha - Rio de Janeiro. No afluente, o $17 \beta$ - estradiol e o estrona foram detectados em concentrações significativas de $21 \mu \mathrm{g} / \mathrm{l}$ e $4 \mu \mathrm{g} / \mathrm{l}$, respectivamente.

Nas estações de tratamento de esgoto da Alemanha, Inglaterra, Holanda e Estados Unidos, as concentrações médias de $17 \alpha$ - etinilestradiol em efluentes domésticos apresentaram-se na faixa de 1 a $3 \mu \mathrm{g} / \mathrm{l}$ aproximadamente ou abaixo do limite de detecção. Apesar das concentrações serem baixas, elas são de extrema importância para o ambiente aquático, levando em conta que atividades estrogênicas in vitro mostraram que a exposição de peixes a uma concentração de somente $0,1 \mu \mathrm{g} / \mathrm{l}$ de $17 \alpha$-etinilestradiol pode provocar feminização de machos de algumas espécies (FERREIRA, 2008).

\section{CONSIDERAÇÕES FINAIS}

Nota-se a ocorrência de hormônios estrógenos em corpos d'água em diversos países o que é preocupante, em razão dos riscos associados a saúde humana e ambiental, seja esta decorrente da água se destinada ao abastecimento da população ou o comprometimento da biota aquática.

Neste contexto, é urgente alertar a opinião pública para os riscos associados à exposição e bioacumulação deste tipo de poluentes e realçar a enorme importância no monitoramento dos sistemas aquáticos, que são os principais veículos de dispersão ambiental.

São necessários estudos que avaliem a importância da inclusão do controle de estrogênios como critério para classificação de água potável de maneira a estabelecer limites a este novo parâmetro.

O monitoramento destes químicos, assim como o uso de novas tecnologias para o tratamento das águas residuais, é importante para a diminuição da contaminação das 


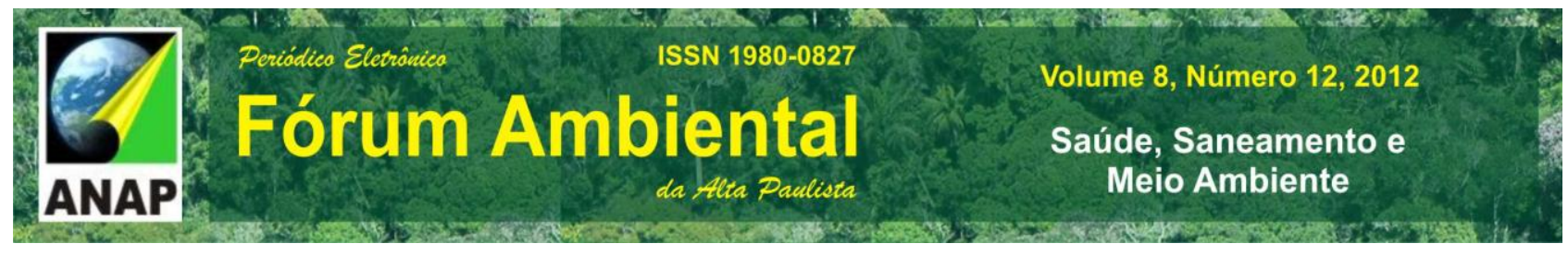

massas de água, assim como da população, já que a água residual tratada poderá ser reutilizada.

Além disso, há a necessidade de se desenvolver técnicas práticas e de menor custo, para que este monitoramento possa ser conduzido efetivamente por agências e prestadores de serviços da área de saneamento.

\section{REFERÊNCIAS}

BIANCHETTI, Fábio José. Remoção do agente hormonalmente ativo etinilestradiol por pré-oxidação e coagulação: estudo em escala de bancada. Dissertação (Mestrado em Saneamento, Meio Ambiente e Recursos Hidricos) Universidade Federal de Minas Gerais, Belo Horizonte, 2008, 107 p.

BURSCH, W. et al. (2004). Endocrine disrupters in the aquatic environment: the Austrian approach." Water Science and Technology, 50(5), 293-300.

FERREIRA, Milena Guedes Maniero. Remoção da atividade estrogênica de 17 $\beta$ estradiol e de 17a-etinilestradiol pelos processos de ozonização. Tese (Doutorado em Ciências em Engenharia Química) Universidade Federal do Rio de Janeiro, 2008, 192 p.

FONTENELE, Eveline Gadelha Pereira et al. Contaminantes ambientais e os interferentes endócrinos. Arq Bras Endocrinol Metab. 2010; 54/1.

FURUICHI, Takuma. et al. Contribution of known endocrine disrupting substances to the estrogenic activity in Tama River water samples from Japan using instrumental analysis and in vitro reporter gene assay. Water Research, 2004, 38(20), 4491-4501.

OTOMO, Juliana Ikebe. Desenvolvimento e validação de metodologia analítica para determinação de hormônio considerados disruptores endócrinos nas águas destinadas ao abastecimento público na região do Rio Paraíba do Sul - SP. Instituto de Pesquisas Energéticas e Nucleares (IPEN), 2010, 186p.

REIS FILHO, Ricardo Wagner. Hormônios sexuais estrógenos: contaminantes bioativos. Química Nova, 2006, 29: 817-822.

SANTOS, João Henrique Zimnoch et al. Desenvolvimento de metodologia analítica para quantificação de fármacos em meio aquático por extração em fase sólida e HPLC. Revista de Ciências Ambientais, Canoas, 2007, v.1, n.2, p. 19 a 34. 
TERNES, Thomas et al. (1999). Polar drug residues in sewage and natural waters in the sate of Rio de Janeiro, Brazil. The Science of the Total Environment, 1999, 225p, $135-141$. 